\title{
The outcome of platelet-rich plasma injection therapy in chronic plantar fasciitis
}

\author{
Upadhyay S. ${ }^{1}$, Kumar Kirar S. ${ }^{2 *}$, Varshney A. ${ }^{3}$, Singh $\mathrm{S.}^{4}$ \\ DOI: https://doi.org/10.17511/ijmrr.2021.i02.09 \\ ${ }^{1}$ Sanjay Upadhyay, Assistant Professor, Department of Orthopaedics, Atal Bihari Vajpayee Government Medical College, Vidisha, Madhya \\ Pradesh, India. \\ 2* Sunil Kumar Kirar, Senior Resident, Department of Orthopaedics, Atal Bihari Vajpayee Government Medical College, Vidisha, Madhya \\ Pradesh, India. \\ 3 Atul Varshney, HOD and Professor, Department of Orthopaedics, Atal Bihari Vajpayee Government Medical College, Vidisha, Madhya \\ Pradesh, India. \\ 4 Sanat Singh, Associate Professor, Department of Orthopaedics, Atal Bihari Vajpayee Government Medical College, Vidisha, Madhya \\ Pradesh, India.
}

Background: Plantar Fasciitis is a frequently encountered problem in the everyday practice of orthopaedics. Treatment of Plantar Fasciitis is challenging to treating surgeon. Various conservative non-invasive treatment modalities are available like rest, casting, night splinting, NSAIDs. If conservative management fails then corticosteroid injection over the medial tuberosity of calcaneum is an effective treatment. But in recent years Platelet-rich plasma (PRP) has proved to be a safe alternative approach with less complication. This study aims to find out the effectiveness of PRP injections in Plantar Fasciitis. Material and Method: In this study, 60 patients with Plantar Fasciitis were included. Regular follow up was done at an interval of 4 weeks, 8 weeks and 6 months after PRP injection. Pain intensity was measured before and after injection on every follow up using the Visual Analogue Scale (VAS). Patients who have undergone at least 4 weeks of conservative treatment were included in the study. Results: After analysis of data, the average VAS score before

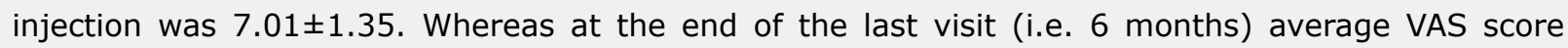
reduced to $2.2 \pm 1.25$. This difference was statistically significant (ANNOVA test $p<0.0001$ ). Conclusion: we concluded that injection of PRP is a safe, convenient and effective approach to treat chronic Plantar Fasciitis.

Keywords: Chronic Plantar Fasciitis, Platelet Rich Plasma, Visual Analogue Scale

Corresponding Author

Sunil Kumar Kirar, Senior Resident, Department of Orthopaedics, Atal Bihari Vajpayee Government Medical College, Vidisha, Madhya Pradesh, India. Email: sunil.meghaniya@gmail.com

\section{How to Cite this Article}

Upadhyay S, Kirar SK, Varshney A, Singh S, The outcome of platelet-rich plasma injection therapy in chronic plantar fasciitis. Int J Med Res Rev. 2021;9(2):104-108.

Available From

https://ijmrr.medresearch.in/index.php/ijmrr/article/ view/1280
To Browse

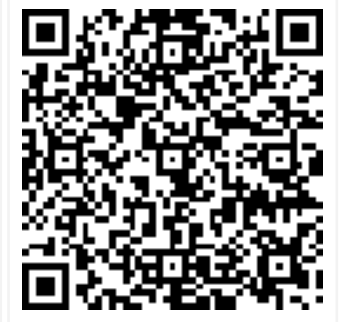

Manuscript Received 2021-04-11

Conflict of Interest No

Review Round 1
2021-04-15
Funding
Nil

Review Round 2
2021-04-25
$\begin{gathered}\text { Ethical Approval } \\ \text { Yes }\end{gathered}$

Review Round 3

Plagiarism X-checker $9 \%$
Accepted 2021-04-29

Note

(C) 2021 by Sanjay Upadhyay, Sunil Kumar Kirar, Atul Varshney, Sanat Singh and Published by Siddharth Health Research and Social Welfare Society. This is an Open Access article licensed under a Creative Commons Attribution 4.0 International License https://creativecommons.org/licenses/by/4.0/ unported [CC BY 4.0]. 


\section{Introduction}

Plantar Fasciitis is one of the most common cause of heel pain encountered in Orthopaedics OPD $[1,2]$. The most common presenting symptom of $\mathrm{PF}$ is a sharp pain of insidious onset with maximal tenderness at the anterior medial border of the calcaneus.[3] Plantar fasciitis affects both sedentary and athletic people and is thought to result from chronic overload either from lifestyle or exercise. [1]. Initially plantar fasciitis was believed to be an inflammatory process, it is now thought to be a degenerative condition and therefore termed as Plantar Fasciosis [4]. .Exact pathology of Plantar Fasciitis is not well understood but there is evidence that Plantar Fasciitis occurs due to repeated microtrauma leading to microscopic tears in the Plantar fascia. There is a combination of repeated opposing forces that act on fascia by the action of tendoachilles and the forefoot. This result in cellular damage exaggerated by vascularity. Various zones of hyperplasia and hypoplasia are developed in fascia [5]. Various treatment options are available to manage Plantar Fasciitis conservatively such as NSAIDS, Stretching exercises, night splinting, orthotics and extracorporeal shockwave therapy. [6]. Corticosteroid injection is used locally to treat Plantar Fasciitis but complications like fascia rupture are frequently associated [7,8]. This side effect is thought to be lesser with PRP (Platelet-rich plasma) due to its autologous nature.[9]. Various growth factors like platelet-derived growth factor, transforming growth factor, vascular endothelial growth factor, insulin-like growth factor and proteins like fibrin, fibronectin, vitronectin are found in PRP. This growth factor helps in soft tissue healing.[10]. Also, PRP stimulates local stem cells and inhibit apoptosis and metalloproteinase activity [11]. Moreover, in tendon recovery it stimulates tenocyte proliferation [12]. This study aimed to find the effectiveness of PRP injections in chronic Plantar Fasciitis.

\section{Material and methods}

The study was conducted at the Department of Orthopaedics, ABVGMC and associated hospital, Vidisha. It was a prospective observational study for a period of 18 months (August 2019 to February 2021). All patients with chronic Plantar Fasciitis age more than 18 years with a history of 4 weeks of unsuccessful conservative treatment visiting orthopaedics OPD were included in the study.
After clinical examination 60 patients who were diagnosed with chronic Plantar Fasciitis were enrolled for the study. Patients without consent are excluded from the study.

\section{Inclusion criteria}

- Patient age 18 years and above.

- Patient with Plantar Fasciitis for at least 6-month duration and not responding to conservative management for at least 4 weeks.

- Pre injection VAS score at least 5 or more.

\section{Exclusion criteria}

- Patient age $<18$ years.

- Foot and ankle dysfunction.

- Infection and bony pathology of the foot.

- Pregnancy.

- Diabetes.

- Patient with a history of any bleeding disorder

Patients were assessed by using a VAS score for pain before and after injection at 4 weeks, 8 weeks and 6month. Platelet-rich plasma preparation method PRP was prepared by withdrawing $40 \mathrm{ml}$ of the patients own blood (autologous). Centrifugation of blood was done at two levels. Initially at $800 \mathrm{rpm}$ for 10 minutes followed by $2400 \mathrm{rpm}$ for 10 minutes.

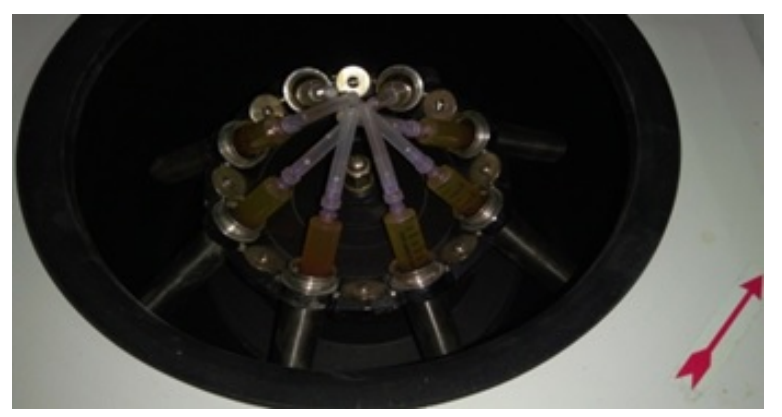

Figure 1: Centrifugation @800 rpm* $10 \mathrm{~min}$

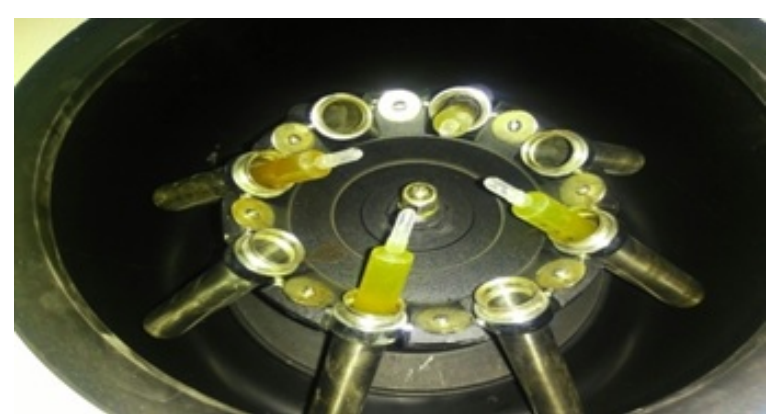

Figure 2: Centrifugation @2400 rpm * $10 \mathrm{~min}$ 
Injection technique- $3 \mathrm{ml}$ PRP solution directly injected into point of maximum tenderness of painful heel using Peppering technique with single skin entry portal. Post injection all patients were advised non-weight bearing for 24 hours and tablet acetaminophen twice daily for 2 days. Gentle stretching exercises were advised before standing after prolonged rest on day 2 i.e. ball roll overexercise, Plantar Fascia stretching exercises. All patients were examined at an interval of 4 weeks, 8 weeks and 6-month post-injection for pain relief on the VAS scale (0-no pain, 10-worst pain).

\section{Results}

A total of 60 patients were included in a study and were followed for 6 months. The age of patients ranged from 20 to 60 years with a mean age of 40 years. The maximum number of patient belonged to the age group 31 to 40 years. Among 60 cases, 21 were male and 39 were female (Graph -1). The right foot was involved in 28 cases and the left foot was involved in 32 cases. Upon analysis we found that there was a significant improvement in pain from 4 weeks post-injection. The Average VAS Score

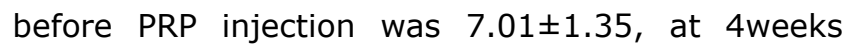
$5.13 \pm 1.32$, at 8 weeks $4.2 \pm 1.31$ and at 6 months $2.2 \pm 1.25$ (Graph -2).

Table 1: showing mean VAS value.

\begin{tabular}{|l|l|l|l|l|}
\hline & Pre injection & 4 weeks & 8 weeks & 6month \\
\hline Mean VAS & 7.01 & 5.13 & 4.2 & 2.2 \\
\hline Standard Deviation & \pm 1.35 & \pm 1.32 & \pm 1.31 & \pm 1.25 \\
\hline
\end{tabular}

The Average VAS score at follow up showed significant improvement in pain relief (Table- $1, p$ value $<0.0001$ ).

\section{Graph 1: showing Sex distribution.}

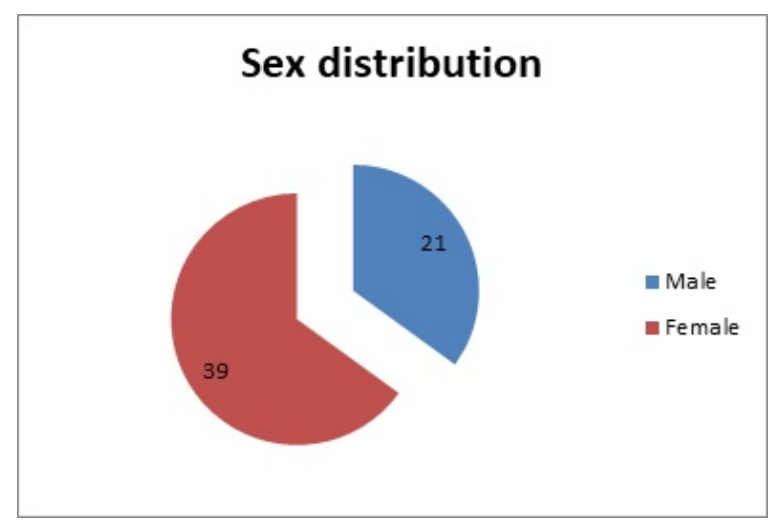

Graph 2: showing a decrease in average VAS value in follow up.

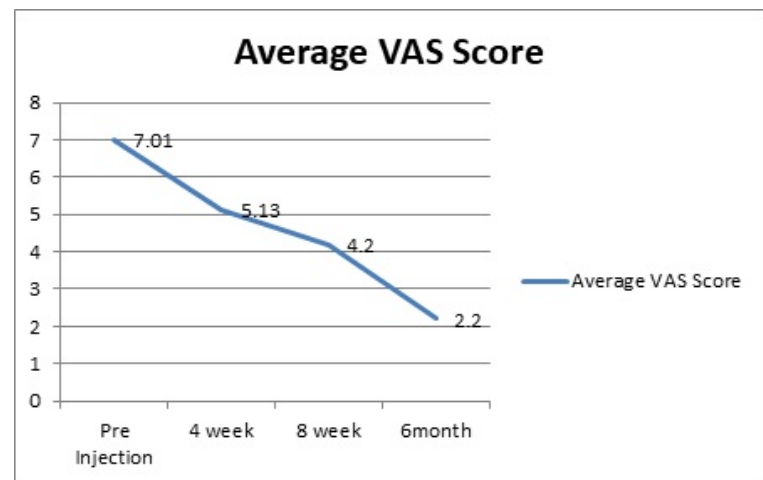

VAS scores at pre-injection and 4 weeks showed a decrease at 4 weeks with a mean difference of 1.88 which was statistically significant where $p$-value $<0.001$. VAS scores at pre-injection and 8 weeks showed a decrease at 8 weeks with a mean difference of 2.81 which was statistically significant where $p$-value $<0.001$. VAS scores at pre-injection and 6 months showed a decrease at 6 months with a mean difference of 4.81 which was statistically significant where $p$-value $<0.001$. Success was defined when there was a reduction in pain without reintervention up to 6 months.

\section{Discussion}

The etiopathogenesis of Plantar Fasciitis is not fully understood. The most acceptable view in the past was that Plantar Fasciitis is an inflammatory process as a result of microtears due to mechanical loading. Conversely, histology showed no evidence of inflammatory cells in the affected area. The normal fascia gets replaced by angiofibrotic hyperplastic tissue which spreads into surrounding tissue and results in a self-perpetuating cycle of degeneration [1]. This study was designed to show the outcome of PRP injection in patients with Plantar Fasciitis.

Gould et al [13]. concluded that VAS is widely used due to its simplicity and adaptability to a broad range of populations and settings. The VAS is more sensitive to small changes, especially when looking at change within individuals. The VAS takes $<1 \mathrm{~min}$ to complete, no training is required other than the ability to use a ruler to measure the distance to determine a score. Our study showed the average VAS score before injection to be $7.01 \pm 1.35$ which reduced significantly to $2.2 \pm 1.25$ ( $\mathrm{p}$-value $<0.001$ ). Another study was done by Nicolo Martinelli et al [14]. showed excellent functional status in $9(64.3 \%)$, good in $2(14.3 \%)$, fair in 2 (14.3\%) and poor in $1(7.1 \%)$. 
The study conducted by Paresh vilasrao et al [15]. in 60 patients showed excellent functional status in 97\% of PRP treated Plantar Fasciitis. In Agreement with our study Gupta et al [16]. and El Mallah et al [17]. suggested PRP is a safe and effective line of treatment for chronic Plantar Fasciitis. Akram et al. [18]. concluded significant improvement in pain according to VAS score and Reduction in thickness of plantar fascia measured by ultrasonography. A metanalysis of RCT conducted by Wei Yi Yang et al [19]. showed PRP is superior to steroid treatment for long term pain relief but no significant difference was observed for short and intermediate effect. However, De Vas et al [20]. studied the effect of PRP in chronic tendinopathy. They concluded that there is no significant improvement of pain by PRP injection compared with saline injection. Similarly Sheath et al [21]. conducted a study to find the efficacy of autologous PRP used for Orthopaedic indications. They conclude the there is uncertainty about evidence in support of PRP used for Orthopaedic bone and soft tissue injuries. A possible explanation according to them is lack of standard study protocol, platelet separation technique and outcome measures. In a study conducted by Tiwari and Bhargava [22]. the cortisone group had a pretreatment mean VAS score of 8.5 , which initially improved to 1.1 at 12 weeks posttreatment to at 26 weeks, and then continuously increased to near baseline levels of 8.4 at 52 weeks. In contrast, the PRP group started with an average pretreatment 8.6 scores decreased to 3.4 at 12 weeks, remained declining to 1.2 at 26 weeks, and 0.3 at 52 weeks.

\section{Conclusion}

We concluded that PRP injections provide symptomatic relief in reducing pain in patients with Plantar Fasciitis. There was a significant improvement in pain reduction according to the VAS score. So PRP therapy is an effective alternative to corticosteroid injection.

\section{What does this study add to existing knowledge?}

PRP injections provide symptomatic relief in reducing pain in patients with Plantar Fasciitis.

\section{Acknowledgements}

The authors would like to thank all the patients for participating in the study

\section{Contributors Details}

SK, SU: conceptualized, manuscript preparation, acquisition, literature research and statistical analysis; SK, SU, AV: analysis, manuscript editing and review, $A \mathrm{~V}, \mathrm{SS}$ provided intellectual inputs to the manuscript; $\mathrm{SU}$ is the guarantor for this paper.

\section{Reference}

01. Schwartz EN, Su J. Plantar fasciitis- a concise review. Perm J. 2014;18(1)e105-7.

DOI: $10.7812 / \mathrm{TPP} / 13-113$ [Crossref]

02. Cole C, Seto C, Gazewood J. Plantar fasciitisevidence-based review of diagnosis and therapy. Am Fam Physician. 2005;72(11)2237-42.

[Crossref]

03. Thomas JL, Christensen JC, Kravitz SR, Mendicino RW, Schuberth JM, Vanore JV, et al. American College of Foot and Ankle Surgeons heel pain committee, The diagnosis and treatment of heel pain- a clinical practice guideline-revision 2010. J Foot Ankle Surg. 2010 May-Jun;49(3 Suppl)S1-19.

doi: 10.1053/j.jfas.2010.01.001 [Crossref]

04. Lemont $H$, Ammirati KM, Usen N. Plantar fasciitis- a degenerative process (fasciosis) without inflammation. J Am Podiatr Med Assoc. 2003 May-Jun;93(3)234-7.

doi: $\quad 10.7547 / 87507315-93-3-234 \quad$ [Crossref]

05. Snider MP, Clancy WG, McBeath AA. Plantar fascia release for chronic plantar fasciitis in runners. Am J Sports Med. 1983 JulAug;11(4)215-9.

doi: $\quad 10.1177 / 036354658301100406 \quad$ [Crossref]

06. Cutts S, Obi N, Pasapula C, Chan W. Plantar fasciitis. Ann R Coll Surg Engl. 2012 Nov; $94(8) 539-42$.

doi: $\quad 10.1308 / 003588412 \times 13171221592456$ [Crossref]

07. Tatli $Y Z$, Kapasi S. The real risks of steroid injection for plantar fasciitis, with a review of conservative therapies. Curr Rev Musculoskelet Med. 2009 Mar;2(1)3-9.

doi: $\quad 10.1007 / \mathrm{s} 12178-008-9036-1 \quad$ [Crossref] 
08. Sellman JR. Plantar fascia rupture associated with corticosteroid injection. Foot Ankle Int. 1994 Jul;15(7)376-81.

doi: $\quad 10.1177 / 107110079401500706 \quad$ [Crossref]

09. Ragab EM, Othman AM. Platelets rich plasma for treatment of chronic plantar fasciitis. Arch Orthop Trauma Surg. 2012 Aug;132(8)1065-70. doi: $\quad 10.1007 / \mathrm{s} 00402-012-1505-8 \quad$ [Crossref]

10. Alsousou J, Thompson M, Hulley P, Noble A, Willett $\mathrm{K}$. The biology of platelet-rich plasma and its application in trauma and orthopaedic surgery- a review of the literature. J Bone Joint Surg Br. 2009 Aug;91(8)987-96.

doi: $10.1302 / 0301-620 X .91 B 8.22546 \quad$ [Crossref]

11. Mishra A, Woodall J Jr, Vieira A. Treatment of tendon and muscle using platelet-rich plasma. Clin Sports Med. 2009 Jan;28(1)113-25.

doi: 10.1016/j.csm.2008.08.007 [Crossref]

12. Baksh N, Hannon CP, Murawski CD, Smyth NA, Kennedy JG. Platelet-rich plasma in tendon models- a systematic review of basic science literature. Arthroscopy. 2013 Mar;29(3)596607.

doi: $\quad 10.1016 / j$.arthro.2012.10.025 [Crossref]

13. Gould D, Kelly D, Goldstone L, Gammon J. Examining the validity of pressure ulcer risk assessment scales- developing and using illustrated patient simulations to collect the data. J Clin Nurs. 2001 Sep;10(5)697-706.

doi: $10.1046 / \mathrm{j} .1365-2702.2001 .00525 . x$ [Crossref]

14. Martinelli N, Marinozzi A, Carnì S, Trovato U, Bianchi A, Denaro V. Platelet-rich plasma injections for chronic plantar fasciitis. Int Orthop. 2013 May;37(5)839-42.

doi: $\quad 10.1007 / \mathrm{s} 00264-012-1741-0 \quad$ [Crossref]

15. Patil Chanchpara, Gunaki, Gaonkar, Gaonkar, Solanki, Alwani, Durgawale Pratik. Platelet rich plasma for plantar fasciitis- Is it a hype???. International Journal of Orthopaedics Sciences. 2017;3;226-230.

DOI 10.22271/ortho.2017.v3.i2d.33 [Crossref]
16. Gupta SKV, Bandari D. Autologous platelet-rich plasma injection in tennis elbow and plantar fasciitis. Current Orthopaedic Practice. 2016;27;405-408.

DOI: $10.1097 / \mathrm{BCO} .0000000000000393$ [Crossref]

17. Mallah R EI, Elattar EA, Zidan HF. Platelet-rich plasma versus dry needling of myofascial meridian trigger points in the treatment of plantar fasciitis. Egyptian Rheumatology \& Rehabilitation. 2017;44;58-68.

DOI: $\quad 10.4103 / 1110-161 \times .205661 \quad$ [Crossref]

18. Moneim Deghady, A A, Abdel Hamid, M M, Hussein Helal, A M, El-Sherif, S M, \& Abdel Latief, $\mathrm{H}$ A. Platelet-rich plasma in treatment of plantar fasciitis- Randomized double-blinded placebo controlled study. Journal of Applied Clinical Pathology. 2019;2(1).

doi:10.24983/scitemed.jacp.2019.00097 [Crossref]

19. Yang WY, Han $Y H$, Cao XW, Pan JK, Zeng LF, Lin JT, Liu J. Platelet-rich plasma as a treatment for plantar fasciitis- A meta-analysis of randomized controlled trials. Medicine (Baltimore). 2017 Nov;96(44)e8475.

doi: $10.1097 / M D .0000000000008475$ [Crossref]

20. de Vos RJ, Weir A, van Schie HT, BiermaZeinstra SM, Verhaar JA, Weinans $H$, Tol JL. Platelet-rich plasma injection for chronic Achilles tendinopathy- a randomized controlled trial. JAMA. 2010 Jan 13;303(2)144-9.

doi: 10.1001/jama.2009.1986 [Crossref]

21. Sheth U, Simunovic N, Klein G, Fu F, Einhorn TA, Schemitsch $E$, et al. Efficacy of autologous platelet-rich plasma use for orthopaedic indications- a meta-analysis. J Bone Joint Surg Am. 2012 Feb 15;94(4)298-307.

doi: 10.2106/JBJS.K.00154 [Crossref]

22. Tiwari M, Bhargava R. Platelet rich plasma therapy- A comparative effective therapy with promising results in plantar fasciitis. J Clin Orthop Trauma. 2013 Mar;4(1)31-5. doi: $10.1016 / j$ j.jcot.2013.01.008 [Crossref] 